\title{
Some Additions to the Sponge Fauna of Plymouth.
}

By

\author{
H. J. H. Borley.
}

With 2 Figures in the Text.

IN a small collection of sponges obtained during the winter of 1930-31 at Plymouth, six specimens were found which are of special interest. Four of these have proved to be new to the locality, the fifth was new to British waters, and the sixth was found to be a new species. Those species new to the Plymouth area are Gellius angulatus (Bowerbank), Pachymatisma johnstoni Bowerbank, Eurypon clavatum (Bowerbank), and Halichondria firmus Bowerbank. The latter is the first example of the species to be recorded since it was first described forty years ago. The species new to the British waters is Reniera aquaductus Schmidt, and the new species Pseudaxinella alleni n.sp.

Unfortunately the interest of the specimens was not fully realised at the time of collection so that only fragments of them were preserved, with the exception of Eurypon clavatum which was a thin plate of about 4 square $\mathrm{mm}$. and of which nothing considerable remained after spicule and skeleton preparations had been made.

I must express my deep gratitude to Dr. Allen for his hospitality and very great help to me at Plymouth, and to Mr. Burton, for his invaluable assistance and advice in the writing of the following notes.

\section{LIST OF SPECIES.}

Pachymatisma johnstoni Bowerbank.

Occurrence.-Mewstone Ledge, Plymouth.

RENIERA AQUeduCtus Schmidt.

R. aquaductus Schmidt, Die Spongien des Adriatischen Meeres, 1862, p. 73, Pl. VII, Fig. 6.

Occurrence.-Mewstone Ledge.

Remarks.-The sponge is made up of 5 upright tubes, $9 \mathrm{~cm}$. high by $1 \mathrm{~cm}$. in diameter, fused together except at the summits. The oscules, $5 \mathrm{~mm}$. in diameter, are apical and are surrounded by a peculiar raised 
margin, now somewhat ragged, but probably smooth originally. The cloaca does not run through the whole tube. The surface is rather uneven in places, and minutely hispid, while the porose appearance, due to the numerous subdermal cavities, is marked. The colour in life is grey, strongly tinged with violet, and turns white in spirit. The texture is firm but compressible. The skeleton is subisodictyal, with a triangular mesh and occasional ill-defined trispiculous fibres. These fibres are seldom long and run irregularly towards the surface. The spicules are oxea measuring $\cdot 132$ by $\cdot 006 \mathrm{~mm}$.

The arrangement of the skeleton and dimensions of the spicules agree closely with those of a specimen of $R$. aqueductus from the Adriatic, identified by Schmidt, and now in the British Museum collection. This specimen is dried, while the present specimen is preserved in alcohol, and in this condition certain dissimilarities were observed. When a fragment of the Plymouth sponge was dried, however, the agreement between the two was found to be very close, and in this way the difference was shown to be apparent only. The Adriatic specimen is tubular, about $30 \mathrm{~cm}$. high by $1 \mathrm{~cm}$. in greatest diameter, narrowing slightly towards the summit and markedly towards the base. The spicules measure $\cdot 132$ by $\cdot 006 \mathrm{~mm}$.

The specimen originally described and figured by Schmidt, now unavailable, was an erect tube $3 \frac{1}{2} \mathrm{~cm}$. by $1 \mathrm{~cm}$., and, in life, violet-blue in colour. Unfortunately, very little is known of this, and our knowledge of the species must depend mainly on the specimens from the same locality, identified by that author.

The main points of difference between the Plymouth sponge and the British Museum specimen are the more massive base and the oscular margin of the former. The presence of the oscular margin is the only considerable difference from the type. Such small differences are, however, hardly sufficient to justify a specific distinction.

Judging by Schmidt's original description the type differs also in the size of the spicules, being $\cdot 165$ by $\cdot 007 \mathrm{~mm}$., but here such a difference has little taxonomic value, especially as the British Museum specimen has spicules identical in size with those of the present specimen. These differences may therefore be regarded simply as evidence of the usual variation in spicule size within the species.

It is probable, judging by several specimens, including some hitherto undescribed, that the arrangement of spicules in the skeleton also shows some variation. In two examples, also in the British Museum, the one from Norway and the other from Cima Island, Madeira, both almost identical with Schmidt's type in external form, and with oxea measuring $\cdot 14$ by $\cdot 004 \mathrm{~mm}$. and $\cdot 149$ by $\cdot 006 \mathrm{~mm}$. respectively, there is a much more regular isodictyal skeleton than in the specimen identified by Schmidt referred to above. 
In spite of certain minor differences, which are perhaps indicative of an ecological variation, the Plymouth sponge must undoubtedly be regarded as a representative of Reniera aquceductus, in which case the geographical range of the species will now include the British Isles, in addition to the Mediterranean, Madeira, Norway, and (possibly ?) Australia.

Distribution. Adriatic ; Black Sea ; Madeira; Norway; British Isles.

Gellius angulatus (Bowerbank) Ridley and Dendy.

Halichondria angulata Bowerbank, Mon. Brit. Spong., 1866, II, p. 233 ; Desmacodes angulatus Vosmaer, Notes Leyden Mus., 1880, II, p. 107 ; Gellius angulatus Ridley and Dendy, Challenger Report Monaxonida, 1887, XX, p. 44 ; Lundbeck Ingolf-Exped. Rep., 1902, VI, 1, p. 62.

Occurrence.-Millbay Channel, Plymouth Sound.

Remarks.-The sponge is massive, globular and sessile, being about $5 \mathrm{~cm}$. high by $10 \mathrm{~cm}$. in diameter, with two oscules $5 \mathrm{~mm}$. in diameter on the upper surface. The surface is very uneven and slightly hispid in places. The dermal membrane is not separable, but is supported by a confusedly subisodictyal skeleton of triangular mesh. The colour, both alive and preserved in spirit, is grey. The texture is friable. Both dermal and choanosomal skeletons are much confused subisodictyal networks with triangular mesh. The spicules are :- oxea 199 by $.008 \mathrm{~mm}$. ; toxa, .063 by $.001 \mathrm{~mm}$., with a rather rounded angle; and minute sigmata, $.009 \mathrm{~mm}$. chord.

The specimen agrees closely in form, colour and texture with the typespecimen in the British Museum. The type differs in having a more open and less confused skeleton, but the only considerable differences are a smoother surface and different spicule measurements. These are as follows :- oxea, $\cdot 225$ to $\cdot 227 \mathrm{~mm}$. by $\cdot 008$ to $\cdot 009 \mathrm{~mm}$.; toxa, $\cdot 063$ to $.072 \mathrm{~mm}$. ; and sigmata, $\cdot 013 \mathrm{~mm}$.

Although the general surface of the Plymouth sponge is more uneven it does in places approach the condition found in the type. Possibly the complete sponge would have shown different surface characters, but in any case this difference alone is hardly enough to justify a separation of the present specimen from $G$. angulatus.

The differences in the sizes of the spicules are also unimportant in view of the known variation within this species. The oxea vary, according to measurements given by various authors, from $\cdot 117$ to $\cdot 388 \mathrm{~mm}$. ; the toxa, from $\cdot 022$ to $.095 \mathrm{~mm}$.; and the sigmata, from 007 to $\cdot 021 \mathrm{~mm}$. The extent of the variation of the sigmata would be increased still further by the inclusion of the second set of sigmata, measuring $.078 \mathrm{~mm}$., found by Lundbeck (l.c.), but the fact that this second category is only recorded 
for this specimen suggests that it is an abnormal form and must be ignored for the present.

The Plymouth sponge approaches most closely those specimens described by Topsent from Luc, in which the measurements of the spicules are :-oxea, $\cdot 160$ to $\cdot 260 \mathrm{~mm}$.; toxa, $\cdot 023$ to $\cdot 070 \mathrm{~mm}$.; and sigmata, $\cdot 007$ to $\cdot 009 \mathrm{~mm}$.

This is the first record of the species from the Plymouth area, though it has been recorded from other points on the British coast.

Distribution.-British Isles; France; Spain; Adriatic; Azores; Iceland.

\section{Eurypon clavatum (Bowerbank).}

Occurrence.-Eddystone Grounds, Plymouth.

\section{HALICHONDRIA FIRMUS Bowerbank.}

Hymeniacidon firmus Bowerbank, Mon. Brit. Spong., 1874, III, p. 186.

Halichondria ambigua Id. t.c., p. 213.

Occurrence.-Winter Shoal, Plymouth Sound.

Remarks.-The sponge consists of thick contorted branches merging into a twisted plate. The branches bear irregular crateriform prominences each with an oscule as a minute opening in the floor of the crater. The surface is markedly glabrous except for deep irregular furrows running up the prominences and converging on the oscules. The dermal membrane is separable and supported by a rather regular network of bundles of spicules with a rhomboidal mesh. The texture is firm and fleshy. The colour in life is yellow, tinged with pink, but the pink disappears in alcohol. The skeleton is typically halichondroid, consisting of oxea, $\cdot 193$ to $\cdot 369 \mathrm{~mm}$. by $\cdot 004$ to $\cdot 009 \mathrm{~mm}$., and occasional styli $\cdot 167$ by $\cdot 006 \mathrm{~mm}$.

This species differs markedly from the two common British species of Halichondria, namely H. panicea (Pallas) and H. bowerbanki Burton, both of which are frequently met with in the Plymouth area. The characteristic features are the external form, the markedly glabrous surface, and the fleshy texture.

Some specimens of $H$. panicea approach $H$. firmus in external form, though not very closely, being distinguished by the greater regularity of the branches when present, and the usually more regular crateriform oscules. H. bowerbanki, on the other hand, is markedly different, but neither of these two have so glabrous a surface, and the texture of both is more friable. These two characteristics serve as a ready means of distinction. The furrowing of the surface is also a well-marked characteristic of $H$. firmus. The spicules are of similar size and shape in all three species, 
but tend to be stouter in $H$. panicea and $H$. bowerbanki than in the present species.

This specimen agrees very closely with Bowerbank's description of the holotype of Halichondria (Hymeniacidon) firmus in all essential respects, and there can be little doubt as to the identity of the two. In point of fact it approaches more closely the type of Halichondria ambigua (Bowerbank), but as there appears to be no considerable difference, judged by the original descriptions, between Halichondria (Hymeniacidon) firmus and $H$. ambigua, there can be little doubt that the two species are synonymous.

Distribution.-British seas.

Genus Pseudaxinella Schmidt.

Genotype.-Pseudaxinella sulcata Schmidt.

(See Schmidt Jahresber. Comm. Unters. d. Meere 1875, V, 2-3, p. 115, and Thiele Arch. Naturg., 1903, I, 3, p. 378.)

Diagnosis.-Axinellidæ with skeleton composed of long curved styli, short bent styli, and oxea ; styli arranged in radial plumose fibres with an axial concentration; fibres connected by oxea and short styli.

Pseudaxinella alleni n. sp. (Figs. 1 and 2).

Occurrence.-Eddystone Grounds.

Diagnosis.-Sponge stipitate, ramose; branches showing some anastomosis and terminating in palmate anther-like portions ; surface strongly hispid and very minutely conulose; dermal membrane aspiculous and separable; colour, living and in spirit, golden-yellow; texture firm axially and soft extra-axially ; skeleton of radial plumose fibres rendering surface hispid, radiating from longitudinal concentration of fibres at axis of branch; fibres composed of long curved styli and short bent styli and connected by short styli and few oxea; spongin plentiful in stalk, sparse in upper branches; spicules, long styli .81 by $.02 \mathrm{~mm}$., oxea $\cdot 27$ by $\cdot 008 \mathrm{~mm}$., and short styli $\cdot 343 \mathrm{by} \cdot 003 \mathrm{~mm}$.

Remarks.-The present species agrees with the genotype in habit and the arrangement of the skeleton. It also agrees in the types and shapes of the spicules present except for the thin styli which are not mentioned for $P$. sulcata. Since these styli appear in the type specimen of the other species of Pseudaxinella, namely $P$. egregia (Ridley), this discrepancy is not serious. It seems probably that they are merely developmental forms and cannot therefore affect the identification. It differs further from $P$. sulcata in the comparative scarcity of the oxea and in the measurements of the spicules and from $P$. egregia in a more hispid, but less conulose 
surface, a less regular skeleton, as well as in the dimensions of the spicules. The comparative scarcity of oxea may not be a real distinguishing feature in view of the tendency, shown in so many of the Axinellidæ, for the proportions of oxea and styli to vary.

The spicule differences are more striking, however, the measurements

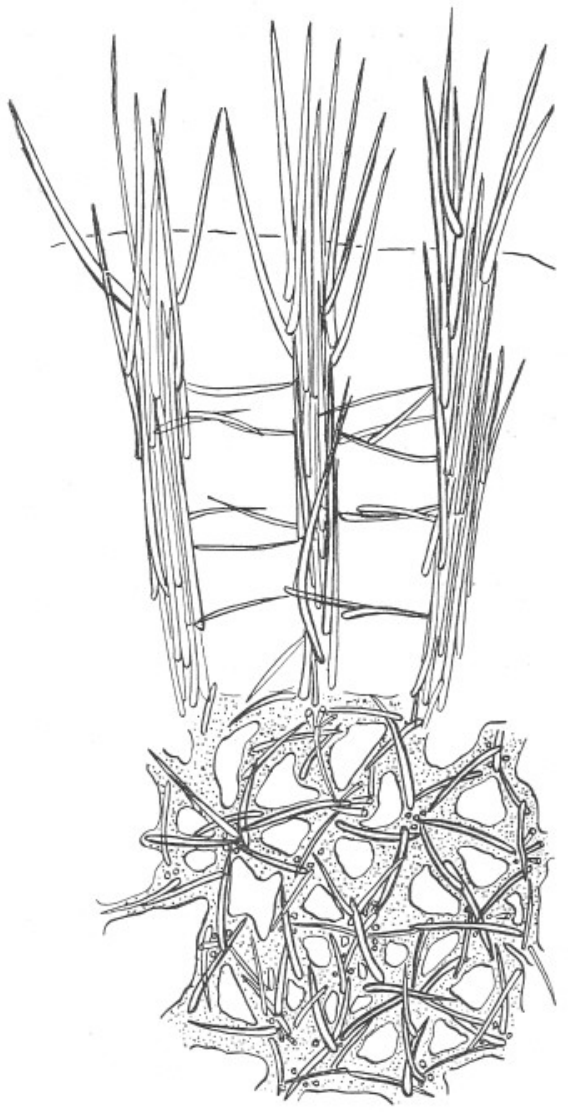

Frg. 1.-Pseudaxinella alleni sp. n. Section at right angles to surface.

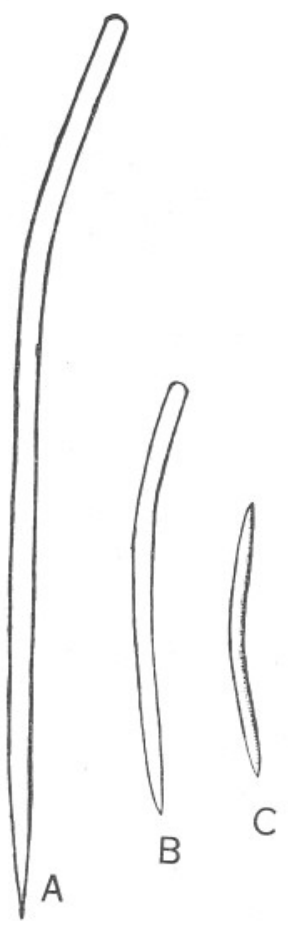

Fia. 2.-Pseudaxinella alleni sp. n.; (a) long style; (b) short style ; (c) oxeote. $\times 22$.

for $P$. sulcata being:-long styli, 1.45 by $.02 \mathrm{~mm}$. ; short styli, 45 by $.02 \mathrm{~mm}$.; and oxea, .55 to $.75 \mathrm{~mm}$. by $\cdot 02 \mathrm{~mm}$. In $P$. egregia the dimensions are :- -long styli, $\cdot 88$ to $1.207 \mathrm{~mm}$. by $\cdot 012$ to $\cdot 019 \mathrm{~mm}$.; short styli, $.253 \mathrm{by} \cdot 009 \mathrm{~mm}$.; and oxea, $\cdot 304$ by $\cdot 012 \mathrm{~mm}$.

Thus the species under consideration does not show a really close agreement with either of the two species so far recorded for the genus. Possibly 
a more extensive collection of specimens might show variations in $P$. sulcata wide enough to include the new species, but in the present state of our knowledge of the genus it seems best to consider this specimen as the type of a new species.

I feel myself that I cannot do better than name this species after Dr. Allen in gratitude for his great help to me personally, and as a slight recognition of his help to other workers in the group. 
